\title{
Fire-retardant-treated low-formaldehyde-emission particleboard made from recycled wood-waste
}

\author{
Song-Yung Wang ${ }^{\text {a }}$, Te-Hsin Yang ${ }^{\text {a }}$, Li-Ting Lin ${ }^{\text {a }}$, Cheng-Jung Lin ${ }^{\text {b }}$, Ming-Jer Tsai ${ }^{\text {a,* }}$ \\ ${ }^{a}$ School of Forestry and Resource Conservation, College of Bio-Resource and Agriculture, National Taiwan University, \\ No. 1, Sec. 4, Roosevelt Road, Taipei 10608, Taiwan, ROC \\ ${ }^{\mathrm{b}}$ Division of Forest Utilization, Taiwan Forestry Research Institute, Taipei, Taiwan, ROC
}

Received 27 January 2007; received in revised form 27 March 2007; accepted 27 March 2007

Available online 15 May 2007

\begin{abstract}
The objective of this study was to manufacture fire-retardant-treated low-formaldehyde-emission particleboard from recycled woodwaste particles using polymeric 4,4'-methylenediphenyl isocyanate (PMDI) and phenol-formaldehyde (PF) resins. The influence of the PMDI/PF ratio (ratio of particles sprayed with PMDI to particles sprayed with PF, w/w) after fire retardant treatment on formaldehyde emissions, mechanical properties, and surface fire resistant performance of the manufactured particleboard was investigated. The experimental results showed that the formaldehyde emissions linearly decreased with an increasing PMDI/PF ratio. Moreover, the bending strength, internal bond strength, and screw holding strength increased with an increasing PMDI/PF ratio. The thickness swelling of the particleboard was improved by using an increasing PMDI/PF ratio. Furthermore, the fire-retardant-treated low-formaldehyde-emission particleboards fabricated in our study could pass the third grade standard of surface fire resistant performance as specified by CNS 6532 .
\end{abstract}

(C) 2007 Elsevier Ltd. All rights reserved.

Keywords: Particleboard; Fire retardant; Recycled wood-waste; Quantity of formaldehyde emissions

\section{Introduction}

The demand for wood composites from waste wood has been increasing as timber resources in natural forests decline. According to the end uses of wood-wastes and their possible reuse products, particleboard has found typical applications as flooring, wall and ceiling panels, office dividers, bulletin boards, furniture, cabinets, counter tops, and desk tops (Wang and Sun, 2002), and it seems that the manufacture of particleboard from recycled wood-based wastes is the most common way to reuse such waste materials (Yang et al., 2007).

During the process of using recycled wood-wastes for further reutilization, some problems should be taken into consideration; for instance, formaldehyde can be released

\footnotetext{
${ }^{*}$ Corresponding author. Tel.: +8862 33664641; fax: +886223686335.

E-mail address: tmj@ntu.edu.tw (M.-J. Tsai).
}

from particleboards used as interior building products due to incompletely reacted urea-formaldehyde (UF), urea-melamine-formaldehyde (UMF), melamine-formaldehyde (MF), or phenol-formaldehyde (PF) resins used in their manufacturing. Nemli and Öztürk (2006) also pointed out that specific gravity, shelling ratio, wood type and press pressure significantly affect the formaldehyde emission of particleboard. Formaldehyde is considered a dangerous substance, and its concentration in indoor environments is restricted in many countries. As wood-based panels are possible sources of formaldehyde emissions, during recent years, a lot of work has evaluated the effects of press conditions (press temperature and time), mat moisture content, lower-molecular-weight UF resins, and the addition of formaldehyde scavengers on formaldehyde emissions, and investigated the manufacture of various wood-based panels using low-formaldehyde and non-formaldehyde resins (Minemura, 1976; Hao and Liu, 1993; Wang and Gardner, 
1999; Grigoriou, 2000; Wiglusz et al., 2002; Wang et al., 2003; Wang et al., 2007).

Moreover, among the properties of wood-based materials, fire retardancy is important for fire safety. The combustibility of wood-based materials can be decreased by fire-retardant (FR) treatment. Many studies have been undertaken to improve the FR properties of wood and wood-based products ( $\mathrm{Su}$ et al., 1997; Getto and Ishihara, 1998; Subyakto et al., 1998; Wang and Rao, 1999; Chuang and Wang, 2002). Surface treatment using FR chemicals was shown to be a simple, effective, and economical method (Su et al., 1997; Subyakto et al., 1998).

The purpose of this study was to evaluate the effects of FR treatment on the quantity of formaldehyde emissions, the density, bending properties, ultrasonic properties, internal bond strength, thickness swelling, screw holding strength, and surface FR performance of particleboards made from recycled wood-waste particles using polymeric 4,4'-methylenediphenyl isocyanate (PMDI) and PF resins.

\section{Methods}

\subsection{Materials}

Particles from mixed hardwood species including oak (Quercus spp.) and lauan (Shorea spp.) (with a mixture ratio of 50:50, w/w) were prepared from recycled construction and demolition wastes, which were collected and then classified by Jen-Chun Enterprises of Feng-Yuan, Taiwan.

For manufacturing low-formaldehyde-emission particleboards, the adhesives used were a water-soluble PF resin (76-78\% solid content and $\mathrm{pH} \mathrm{8-9;} \mathrm{Tai-Lin} \mathrm{Resin,} \mathrm{Taipei,}$ Taiwan) and a water-soluble PMDI resin (100\% solid content; Mu-Chau Resin, Tainan, Taiwan).

Two FR chemicals were used for manufacturing FRtreated low-formaldehyde-emission particleboards. The first chemical (called FR1) was developed in our former study (Chuang and Wang, 2002) and is a mixture of ammonium phosphate, diammonium phosphate, ammonium sulfate, borax, boric acid, and ammonium bromide, in the ratio of 20:23:40:1:1:15, and with a specific gravity of 1.1. A FR chemical solution with a concentration of $30 \%$ solid weight was used. The second chemical (called FR2) was an oil-based paint (containing chloride, inflammable emulsion resin, phosphide, titan white, and other volatile components; with a $65 \%$ solids content; Yung-Chi Paint, Taipei, Taiwan) and was only used for comparing the surface FR performance with FR1-treated particleboards.

\subsection{Particleboard production process}

Particles were divided into coarse particles, which passed through a 4-mesh screen and were retained by an 8-mesh screen, and fine particles, which passed through an 8 -mesh screen and were retained by a 20 -mesh screen. The particles were first spayed with FR1. The FR1 absorption was $15 \%$ of the oven-dried weight of the particles. The particles were then dried to a $2-4 \%$ moisture content (MC) at a temperature of $65 \pm 2{ }^{\circ} \mathrm{C}$ in an oven. They were then sprayed with a water-soluble PMDI or PF resin according to the various PMDI/PF ratios (ratio of particles sprayed with PMDI to particles sprayed with $\mathrm{PF}$, w/w), shown as 100/0 (4.0\% PMDI- and 0.0\% PF-resin content), 80/20 (3.2\% PMDI- and 1.2\% PF-resin content), 70/30 (2.8\% PMDI- and 1.8\% PF-resin content), 50/50 (2.0\% PMDIand $3.0 \%$ PF-resin content), 30/70 (1.2\% PMDI- and $4.2 \%$ PF-resin content), $20 / 80(0.8 \%$ PMDI- and $4.8 \%$ PF-resin content), and 0/100 (0.0\% PMDI- and 6.0\% PFresin content), respectively.

Particles were then placed into a frame of $500 \mathrm{~mm} \times 500 \mathrm{~mm}$. Three-layer particle-mat was formed using coarse particles for the core layer and fine particles for the face and back layers. The ratio of coarse/fine particles used for the particleboards was 2:1 (w/w). A conventional one opening hot press was used to fabricate the particleboard, and the temperature, pressure, and pressing time were $180^{\circ} \mathrm{C}, 2.9 \mathrm{MPa}$ and $5 \mathrm{~min}$, respectively. The nominal dimensions of the particleboard were $500 \mathrm{~mm} \times 500 \mathrm{~mm} \times 12 \mathrm{~mm}$ (thick), with three layers. The thickness of the particleboard was controlled by stop bars, and the target density was $0.8 \mathrm{~g} / \mathrm{cm}^{3}$. Five samples of each PMDI/PF ratio were fabricated in this study.

Another group of FR-treated particleboards was prepared from particles onto which no FR1 was sprayed. However, painting with FR2 followed fabrication of the particleboards described above and was only used for comparing the surface FR performance with FR1-treated particleboards. The absorption content was $727 \mathrm{~g} / \mathrm{m}^{2}$, and the paint layer thickness was $0.25 \mathrm{~mm}$.

\subsection{Test methods}

The particleboards produced for this study were mainly tested in accordance with the Chinese National Standards CNS 2215 (2006) and CNS 6532 (2006), which involve various tests.

\subsubsection{Test for the quantity of formaldehyde emissions}

2.3.1.1. Acquisition of formaldehyde. A 120-mm-diameter, $60-\mathrm{mm}$-high crystallizing dish containing $300 \mathrm{~mL}$ of distilled water was placed in the bottom of a 240 -mm-diameter desiccator with a capacity of $10 \pm 1 \mathrm{~L}$. Nine pieces of test specimens (with dimensions of $12 \times 50 \times 150 \mathrm{~mm}$ ) were clamped in a metal support, with no contact between specimens and allowed to stand on the perforate plate located over crystallizing dish in the desiccators at $20^{\circ} \mathrm{C}$ for $24 \mathrm{~h}$. Formaldehyde emissions from the specimens was absorbed by the distilled water, which was subsequently used as the sample solution.

2.3.1.2. Quantification of formaldehyde concentration. The formaldehyde concentration in the sample solution was determined using an acetylacetone-ammonium acetate 
solution and the acetylacetone method, with colorimetric detection at $415 \mathrm{~nm}$.

\subsubsection{Ultrasonic wave test}

A series of studies was conducted to investigate the use of non-destructive evaluation (NDE) technologies to aid in the quality assessment of wood-based products (Ross and Pellerin, 1988; Sun and Arima, 1999). These studies yielded similar results and established relationships between the mechanical strength and dynamic properties.

Prior to testing, the particleboards were conditioned at $20^{\circ} \mathrm{C}$ and $65 \%$ relative humidity, and full panels of each particleboard were prepared for ultrasonic wave tests. Test points on opposite sides of the particleboard were investigated at intervals of $50 \mathrm{~mm}$. An ultrasonic wave instrument (Pundit, $54 \mathrm{kHz}$; CNS Electronics) was used to measure the time required for the transmission of an ultrasonic pulse through the specimen. The ultrasonic velocity was then calculated from the length of the specimen divided by the propagation time.

After the ultrasonic investigation, the particleboards tested were cut into specimens for static bending and internal bond strength (IB) tests according to CNS 2215, and their positions relative to the full particleboard were recorded. These static bending specimens were first used to measure the ultrasonic velocity $\left(V_{1}\right)$ through the lengthwise direction using a Pundit ultrasonic apparatus at a frequency of $54 \mathrm{kHz}$. Then transit times for the ultrasonic pulse were measured at a frequency of $500 \mathrm{kHz}$ through the thickness of each specimen. The velocity was then calculated using the following formula:

$V_{1}\left(V_{\mathrm{t}}\right)(\mathrm{m} / \mathrm{s})=\frac{L}{t}$,

where $V_{1}$ is the ultrasonic velocity in the lengthwise direction of the particleboard, $V_{\mathrm{t}}$ is the ultrasonic velocity through the thickness of the particleboard, $L$ is the length, and $t$ is the transit time.

\subsubsection{Density, static bending strength, internal bond strength, thickness swelling, and screw holding strength}

Fabricated particleboards were conditioned at $20 \pm 3{ }^{\circ} \mathrm{C}$ and $65 \pm 5 \%$ relative humidity until they had a moisture content of about $12 \%$ and then tested for density, static bending strength, internal bond strength, thickness swelling, and screw holding strength (SH) according to CNS 2215.

After the ultrasonic wave tests, bending specimens of $50 \mathrm{~mm}$ wide $\times 230 \mathrm{~mm}$ long were cut from each full particleboard. A concentrated bending load was applied to the center with a span of 15 times the thickness of the specimen. The proportional limit, ultimate load, and deflection were obtained from the load-deflection curves, and the bending modulus of elasticity (MOE) and modulus of rupture (MOR) were calculated.

The tensile strength perpendicular to the surface was determined using three conditioned specimens of $50 \mathrm{~mm} \times$ $50 \mathrm{~mm}$ from each particleboard, and the internal bond strength was calculated.
Specimens with dimensions of $50 \mathrm{~mm} \times 50 \mathrm{~mm}$ were prepared for evaluation of the thickness swelling. The thickness at the middle of the test specimen was measured with a micrometer. Then the test specimens were placed in water in parallel at a 30-mm depth and soaked for $2 \mathrm{~h}$ and $24 \mathrm{~h}$ before further measurement of the thickness.

\subsubsection{Surface fire-retardant (FR) performance}

Before the surface FR test, the particleboards were dried at $40 \pm 1{ }^{\circ} \mathrm{C}$ over $48 \mathrm{~h}$, and then conditioned in a desiccator containing silica gel for $24 \mathrm{~h}$. A Toyo SEIKI model F2-RE3 fire-retardant tester for building materials was used for the test. The third grade of surface FR performance of all specimens was evaluated according to the rules specified by the CNS 6532 standard, in which the specimens were heated $3 \mathrm{~min}$ using sub-heat (liquid propane gas) and heated an additional 3 min by a main heater (electric heater). Total heating time was $6 \mathrm{~min}$.

According to the standard of the third grade surface FR performance as specified by CNS 6532, the specimens must meet the following specifications after $6 \mathrm{~min}$ of heating: (1) $t_{\mathrm{c}}$ values considered to be the combustibility index of the material must be more than $180 \mathrm{~s}$; (2) $t \mathrm{~d} \theta$ values considered to be the burning heat quantity index of the material must be less than $350 \mathrm{~min} \cdot{ }^{\circ} \mathrm{C}$; (3) $\mathrm{C}_{\mathrm{A}}$ values considered to be the smoking quantity index of the material must be less than 120; and (4) $t$ l values considered to be the flame lingering time index of the material must be less than $30 \mathrm{~s}$.

\section{Results and discussion}

\subsection{Quantity of formaldehyde emissions}

In this study, FR1-treated particles of mixed wood species were sprayed with a water-soluble PMDI or PF resin according to the various PMDI/PF ratios. It was found that the quantity of formaldehyde emissions decreased with an increasing PMDI/PF ratio. The relationship could be represented by the following linear regression formula: formaldehyde emissions $(\mathrm{mg} / \mathrm{L})=-0.0070 \quad(\mathrm{PMDI} / \mathrm{PF}$ ratio $)+0.787\left(R^{2}=0.98, \quad F=142^{* *}\right)$. For FR1-treated specimens, with various PMDI/PF ratios, the quantity of formaldehyde emissions was less than $0.80 \mathrm{mg} / \mathrm{L}$, which met the $\mathrm{F}_{3}$ standard $(<1.50 \mathrm{mg} / \mathrm{L})$ of $\mathrm{CNS} 2215$. For FR1-treated specimens, with a PMDI/PF ratio of 50/50, the quantity of formaldehyde emissions was $0.48 \mathrm{mg} / \mathrm{L}$, which met the $\mathrm{F}_{2}$ standard $(<0.50 \mathrm{mg} / \mathrm{L})$ of CNS 2215 . Moreover, the quantity of formaldehyde emissions was $0.26 \mathrm{mg} / \mathrm{L}\left(<0.30 \mathrm{mg} / \mathrm{L} ; \mathrm{F}^{* * * *}\right.$ of JIS A 5908) from FR1treated samples with a PMDI/PF ratio of 70/30. According to the statistical analysis, significant differences $(p<0.05)$ did not exist for the quantity of formaldehyde emissions from the low-formaldehyde-emission particleboards fabricated in our previous study (Wang et al., 2007) and that released from FR1-treated low-formaldehyde-emission particleboards fabricated in this study. 


\subsection{Bending properties and ultrasonic velocity}

FR1-treated low-formaldehyde-emission particleboards, with PMDI/PF ratios of 50/50 (FD group), 70/30 (FC group), and 100/0 (FA group), were prepared for the following investigations.

Results of the bending properties and ultrasonic velocity $\left(V_{1}\right)$ of specimens are listed in Table 1 . It is evident that MOR and MOE values increased with an increasing $\mathrm{PMDI} / \mathrm{PF}$ ratio. In comparison to the bending properties of low-formaldehyde-emission particleboards with the same PMDI/PF ratio in our previous study (Wang et al., 2007), the MOR values for groups FD, FC, and FA were $9.76 \%, 8.82 \%$ and $20.55 \%$ lower, whereas the MOE values were $11.72 \%, 13.70 \%$ and $13.97 \%$ lower, respectively. MOR values for samples in groups FD and FC met standard 13 $(\mathrm{MOR}>13 \mathrm{MPa})$ of CNS 2215. Furthermore, the MOR values for group FA met standard $18(\mathrm{MOR}>18 \mathrm{MPa})$ of CNS 2215. With regard to MOE values, group FA samples met standard 13 (2499 MPa), whereas groups FD and FC only met standard 8 (1999.2 MPa) of CNS 2215.

Values for the ultrasonic velocity $\left(V_{1}\right)$ are shown in Table 1 . It is evident that the ultrasonic velocity propagated in the lengthwise direction $\left(V_{1}\right)$ increased with an increasing PMDI/PF ratio. In addition, there was a significant positive relationship between the ultrasonic velocity and the bending strength, as shown in Table 2 .

\subsection{Internal bond strength}

A high internal bond strength (IB) was observed for FR1-treated particleboards with different PMDI/PF ratios in our study because of the even distribution of the PMDI/ PF resin on the particles. Bao et al. (2003) indicated that

Table 1

Air-dried density, modulus of rupture (MOR), modulus of elasticity (MOE), ultrasonic velocity propagated through the lengthwise direction $\left(V_{1}\right)$, internal bond strength (IB), screw holding strength (SH), thickness swelling (TS) and ultrasonic velocity propagated through the thickness $\left(V_{\mathrm{t}}\right)$ of fire-retardant-treated low-formaldehyde-emission particleboard

\begin{tabular}{lccc}
\hline Property & $\begin{array}{l}\text { Fire-retardant-treated low-formaldehyde-emission } \\
\text { particleboard }\end{array}$ \\
& PMDI/PF ratio & \\
\cline { 2 - 4 } & $\begin{array}{l}50: 50(\mathrm{FD} \\
\text { group) }\end{array}$ & $\begin{array}{l}70: 30(\mathrm{FC} \\
\text { group) }\end{array}$ & $\begin{array}{l}100: 0(\mathrm{FA} \\
\text { group) }\end{array}$ \\
\hline Air-dried density & $0.83 \pm 0.05^{\mathrm{a}}$ & $0.81 \pm 0.06^{\mathrm{a}}$ & $0.80 \pm 0.05^{\mathrm{a}}$ \\
$\quad\left(\mathrm{g} / \mathrm{cm}^{3}\right)$ & & & \\
MOR $(\mathrm{MPa})$ & $14.5 \pm 1.4^{\mathrm{a}}$ & $16.9 \pm 2.2^{\mathrm{b}}$ & $18.4 \pm 3.1^{\mathrm{c}}$ \\
MOE $\left(\times 10^{2} \mathrm{MPa}\right)$ & $22.1 \pm 2.6^{\mathrm{a}}$ & $22.9 \pm 3.6^{\mathrm{b}}$ & $26.5 \pm 3.3^{\mathrm{c}}$ \\
$V_{1}(\mathrm{~m} / \mathrm{s})$ & $1583 \pm 165^{\mathrm{a}}$ & $1682 \pm 204^{\mathrm{b}}$ & $1868 \pm 193^{\mathrm{c}}$ \\
IB $(\mathrm{MPa})$ & $0.24 \pm 0.07^{\mathrm{a}}$ & $0.31 \pm 0.06^{\mathrm{ab}}$ & $0.34 \pm 0.12^{\mathrm{b}}$ \\
SH $(\mathrm{N})$ & $403.8 \pm 67.1^{\mathrm{a}}$ & $577.2 \pm 42.9^{\mathrm{b}}$ & $746.8 \pm 80.5^{\mathrm{c}}$ \\
TS $(\%)$ & $11.9 \pm 1.2^{\mathrm{a}}$ & $11.3 \pm 1.5^{\mathrm{a}}$ & $6.4 \pm 2.2^{\mathrm{b}}$ \\
$V_{\mathrm{t}}(\mathrm{m} / \mathrm{s})$ & $585 \pm 85^{\mathrm{a}}$ & $601 \pm 64^{\mathrm{a}}$ & $665 \pm 151^{\mathrm{a}}$ \\
\hline
\end{tabular}

PMDI/PF ratio, ratio of particles sprayed with PMDI to particles sprayed with $\mathrm{PF}, \mathrm{w} / \mathrm{w}$.

Results are given as the mean $\pm \mathrm{SD}$. In the same row, means with the same superscript letter(s) do not significantly differ at $p=0.05$.
Table 2

Correlation among the quantity of formaldehyde emissions (FR), PMDI/ PF ratio, ultrasonic velocity ( $V$ ), modulus of rupture (MOR), modulus of elasticity (MOE), internal bond strength (IB), and screw holding strength (SH) analyzed by linear regression $(Y=A X+B)$ formulae for the tested particleboards

\begin{tabular}{llllllll}
\hline Sample & \multicolumn{2}{l}{$Y=A X+B$} & & & & \\
\cline { 2 - 7 } & $Y$ & $X$ & $A$ & $B$ & $r^{2}$ & $F$ \\
\hline $\begin{array}{l}\text { Fire-retardant-treated } \\
\text { low-formaldehyde- }\end{array}$ & FR & PMDI/ & -0.0070 & 0.787 & 0.98 & $142^{* *}$ \\
emission & & PF & & & & \\
particleboard & MOR & $V_{1}$ & 0.01 & -3.28 & 0.79 & $307^{* *}$ \\
& MOE & $V_{1}$ & 0.01 & 1.51 & 0.60 & $121^{* *}$ \\
& IB & $V_{\mathrm{t}}$ & 0.0008 & -0.178 & 0.78 & $200^{* *}$ \\
& SH & $V_{\mathrm{t}}$ & 1.2 & -293.8 & 0.83 & $269^{* *}$ \\
\hline
\end{tabular}

FR, quantity of formaldehyde emissions (mg/L); PMDI/PF ratio, ratio of particles sprayed with PMDI to particles sprayed with PF, w/w; MOR, modulus of rupture; MOE, modulus of elasticity; IB, internal bond strength; $\mathrm{SH}$, screw holding strength; $V_{\mathrm{l}}$, ultrasonic velocity propagated through the lengthwise direction of the particleboard; $V_{\mathrm{t}}$, ultrasonic velocity propagated through the thickness of the particleboard.

** Significant difference at the $1 \%$ level $(p<0.01)$.

the major components formed from the curing of PMDI in wood are urea structures arising from the reaction with water. PMDI can penetrate into wood cells and into the middle lamellae between the wood cells, where it reacts with the available moisture stored in the wood to form either linear urea structures and/or crosslinking biuret/ dimmer/trimer structures. In addition, PMDI may react with the chemical components (the hydroxyl groups in polysaccharide or the lignin phenolic groups) of the wood to form urethane structures, which likely further contribute to adhesion. The IB values of the specimens of FD, FC, and FA group in our study were 0.24, 0.31, and $0.34 \mathrm{MPa}$, respectively (Table 1 ), which meet standard 13 (0.21 MPa) of CNS 2215. Johns et al. (1981) compared densities of particleboards, manufactured using PMDI, EMDI, UF, and PF resin, and results indicated that the IB values of particleboards manufactured using PMDI and EMDI resin were higher than those of particleboards manufactured using UF and PF resin. However, compared to particleboard manufactured from mixed species (IB = 0.56 MPa) (Xu and Suchsland, 1998), and low-formaldehyde-emission particleboard in our previous study (IB = 0.56-0.73 MPa) (Wang et al., 2007), the IB values of FR1-treated particleboard in this study were lower.

As shown in Table 2, IB values increased linearly with an increasing ultrasonic velocity through the thickness of FR1-treated particleboard. This result is in agreement with a previous study of particleboards in which a high correlation was reported between the ultrasonic velocity measured along the length or thickness and the IB, with $R^{2}$ values of 0.66 and 0.92 , respectively (Sun and Arima, 1998). Previous studies also indicated a high degree of correlation between the ultrasonic velocity propagated through the thickness and the IB of PF resin-impregnated OSB (Wang et al., 2007; Yang et al., 2001). This suggests that the ultrasonic velocity can satisfactorily be used to assess the IB of FR1-treated particleboards. 


\subsection{Thickness swelling}

Results for the thickness swelling of FR1-treated particleboards manufactured in our study for groups FA, FC, and FD were lower than $12 \%$ (Table 1) and met standard 8 of CNS 2215. Table 1 also shows that the thickness swelling decreased with an increasing PMDI/PF ratio. The reason for this relationship is possibly a swelling effect induced by PMDI. In comparison to the thickness swelling of the low-formaldehyde-emission particleboards tested in our former study (Wang et al., 2007), the thickness swelling for FR1-treated particleboards fabricated in this study was lower. However, no significant effect of FR1 treatment on thickness swelling was observed between them.

\subsection{Screw holding strength}

Table 1 shows that the screw holding strength $(\mathrm{SH})$ of particleboards manufactured in our study was 403.8$746.8 \mathrm{~N}$, which was significantly lower than values measured for low-formaldehyde-emission particleboards $(638.0-848.7 \mathrm{~N})$ in our previous study (Wang et al., 2007). Moreover, compared to the quality of particleboard type 18 according to the CNS 2215 standard $(500.1 \mathrm{~N})$, higher SH values were observed for FR1-treated particleboard groups FA and FC in this study. Moreover, SH values increased with an increasing PMDI/PF ratio. The results could be represented by linear formulae, as shown in Table 2. Table 2 also shows that there was a high degree of correlation between the $\mathrm{SH}$ and the ultrasonic velocity.

\subsection{Surface fire-retardant performance}

The surface FR performance of FR1-treated and FR2painted low-formaldehyde-emission particleboards sprayed with various PMDI/PF ratios is shown in Table 3. The $t_{\mathrm{c}}$ values of 211-225 s for FR1-treated samples and $>360 \mathrm{~s}$ for FR2-painted samples were greater than the required

Table 3

Effects of FR1 and FR2 chemicals on surface fire-retardant performance indexes of FR-treated low-formaldehyde-emission particleboard

\begin{tabular}{|c|c|c|c|c|c|c|}
\hline Sample & $\begin{array}{l}\text { PMDI/ } \\
\text { PF } \\
\text { ratio }\end{array}$ & $\begin{array}{l}\text { Thickness } \\
(\mathrm{mm})\end{array}$ & $t_{\mathrm{c}}(\mathrm{s})$ & $\begin{array}{l}t \mathrm{~d} \theta \\
\left(\min \cdot{ }^{\circ} \mathrm{C}\right)\end{array}$ & $\mathrm{C}_{\mathrm{A}}$ & \\
\hline $\begin{array}{l}\text { FR1-treated low- } \\
\text { formaldehyde- } \\
\text { emission } \\
\text { particleboard }\end{array}$ & $\begin{array}{l}100: 0 \\
70: 30 \\
50: 50\end{array}$ & $\begin{array}{l}12.4 \\
12.1 \\
12.3\end{array}$ & $\begin{array}{l}219 \\
225 \\
211\end{array}$ & $\begin{array}{l}4.1 \\
3.9 \\
4.6\end{array}$ & $\begin{array}{l}30.0 \\
28.5 \\
31.5\end{array}$ & $\begin{array}{l}2 \\
3 \\
2\end{array}$ \\
\hline $\begin{array}{l}\text { FR2-painted low- } \\
\text { formaldehyde- } \\
\text { emission } \\
\text { particleboard }\end{array}$ & $\begin{array}{l}100: 0 \\
70: 30 \\
50: 50\end{array}$ & $\begin{array}{l}12.7 \\
12.6 \\
12.5\end{array}$ & $\begin{array}{l}>360 \\
>360 \\
>360\end{array}$ & $\begin{array}{l}0 \\
0 \\
0\end{array}$ & $\begin{array}{l}10.5 \\
10.5 \\
10.5\end{array}$ & $\begin{array}{l}0 \\
0 \\
0\end{array}$ \\
\hline
\end{tabular}

FR1 was a mixture of ammonium phosphate, diammonium phosphate, ammonium sulfate, borax, boric acid and ammonium bromide, in a ratio of 20:23:40:1:1:15. FR2 was an oil-based paint. Its ingredients included chloride, inflammable emulsion resin, phosphide, titan white, and other volatile components.
$180 \mathrm{~s} ; t \mathrm{~d} \theta$ values of $3.9-4.6 \mathrm{~min} \cdot{ }^{\circ} \mathrm{C}$ for FR1-treated samples and $0 \mathrm{~min} \cdot{ }^{\circ} \mathrm{C}$ for FR2-painted samples were less than the CNS 6532 standard of $350 \mathrm{~min} \cdot{ }^{\circ} \mathrm{C}$; $t$ l values of 2 or $3 \mathrm{~s}$ for FR1-treated samples and $0 \mathrm{~s}$ for FR2-painted samples were less than the minimum $30 \mathrm{~s}$; the $\mathrm{C}_{\mathrm{A}}$ value of 28.5 31.5 for FR1-treated samples and 10.5 for FR2-painted samples were less than 120; the thickness shrinkage of fabricated particleboards was not observed; and cracking did not occur on the back side of any specimens. The FR1treated and FR2-painted low-formaldehyde-emission particleboards could, therefore, pass the third grade standard of surface FR performance as specified by CNS 6532 .

\section{Conclusions}

This study investigated the quantity of formaldehyde emissions and the properties of FR1-treated particleboard produced using recycled wood-waste particles with different PMDI/PF ratios. Results showed that $0.48 \mathrm{mg} / \mathrm{L}$ of formaldehyde was released for group FD samples (with a $\mathrm{PMDI} / \mathrm{PF}$ ratio of 50/50), which met the $\mathrm{F}_{2}$ standard of CNS 2215, whereas for samples with a PMDI/PF ratio of up to $70 / 30$, less than $0.3 \mathrm{mg} / \mathrm{L}$ formaldehyde was released.

The bending properties of FR1-treated particleboards were influenced by the FR treatment. However, the MOR values for samples in groups FD and FC met standard 13 of CNS 2215. Furthermore, the MOR values for group FA met standard 18 of CNS 2215. With regard to MOE values, group FA samples met standard 13, whereas groups FD and FC could only meet standard 8 of CNS 2215. The IB, TS, and SH results for all FR1-treated particleboard samples could meet standards 13,8 , and 18 of CNS 2215, respectively.

The $V_{1}$ increased linearly with increasing MOR and MOE values. However, the $V_{\mathrm{t}}$ increased linearly with increasing IB and SH values. Furthermore, the FR1-treated and FR2-painted low-formaldehyde-emission particleboards fabricated in this study could pass the third grade standard of surface FR performance as specified by CNS 6532 .

\section{Acknowledgements}

The authors thank the Forestry Bureau, Council of Agriculture, Executive Yuan, ROC for financial support under grant 93AS-2.3.3-FB-e1.

\section{References}

Bao, S., Daunch, W.A., Sun, Y., Rinaldi, P.L., Marcinko, J.J., Phanopoulos, C., 2003. Solid state two-dimensional NMR studies of polymeric diphenylmethane diisocyanate (PMDI) reaction in wood. Forest Products Journal 53 (6), 63-71.

Chuang, H.B., Wang, S.Y., 2002. Effects of retention and distribution of fire retardant chemical on performance of fire retardant treated China fir (Cunninghamia lanceolata) wood. Holzforschung 56, 209-214.

Chinese National Standard CNS 2215. Particleboards. Bureau of Standards, Metrology and Inspection, Taipei, Taiwan, 2006. 
Chinese National Standard CNS 6532. Method of test for the fireresistibility of internal decorative material of building. Bureau of Standards, Metrology and Inspection, Taipei, Taiwan, 2006.

Getto, H., Ishihara, S., 1998. Functionally graded wood in fire endurance with basic nitrogen compounds and phosphoric acid. Fire and Materials 22, 77-83.

Grigoriou, A.H., 2000. Straw-wood composites bonded with various adhesive systems. Wood Science and Technology 34, 355-365.

Hao, B.Y., Liu, Zh.T., 1993. The primary study on straw particleboard. Wood Industry 7 (3), 2-6.

Johns, W.E., Maloney, T.M., Huffaker, E.M., Saunders, J.B., Lentz, M.T., 1981. Isocyanate binders for particle-board manufacture. In: Maloney, T.M. (Ed.), Proceedings of the $15^{\text {th }}$ Washington State University International Symposium on Particle Board. Washington State University, Pullman, WA, pp. 213-239.

Minemura, N., 1976. To lessen formaldehyde liberation from the urea resin glued plywood. Wood Industry 31 (12), 8-12.

Nemli, G., Öztürk, I., 2006. Influences of some factors on the formaldehyde content of particleboard. Building and Environment 41 (6), 770 774.

Ross, R.J., Pellerin, R.F., 1988. NDE of wood based composites with longitudinal stress wave. Forest Products Journal 38 (5), 39-45.

Subyakto, Kajimoto, T., Hata, T., Ishihara, S., Kawai, S., Getto, H., 1998. Improving fire retardancy of fast growing wood by coating with fire retardant and surface densification. Fire and Materials 22, 207212.

Su, W.Y., Subyakto, Hata, T., Imamura, Y., Ishihara, S., 1997. Improvement of the fire retardancy of strandboard by surface treatment with melamine and boric or phosphoric acids. Mokuzai Gakkaishi 43, 75-81.

Sun, Y.G., Arima, T., 1998. Structural mechanics of wood composite materials I: Ultrasonic evaluation of internal bond strength during an accelerated aging test. Journal of Wood Science 44 (5), 348-353.
Sun, Y.G., Arima, T., 1999. Structural mechanics of wood composite materials II: Ultrasonic propagation mechanism and internal bonding of particleboard. Journal of Wood Science 45 (3), 221-226.

Wang, W.L., Gardner, D.J., 1999. Investigation of volatile organic compound press emissions during particleboard production. Part I. UF-bonded southern pine. Forest Products Journal 49 (3), 65-75.

Wang, S.Y., Rao, Y.C., 1999. Structural performance of fire retardant treated plywood: effect of elevated temperature. Holzforschung 53, $547-552$.

Wang, D., Sun, X.S., 2002. Low density particleboard from wheat straw and corn pith. Industrial Crops and Products 15, 47-50.

Wang, W.L., Gardner, D.J., Baummann, M.G.D., 2003. Factors affecting volatile organic compound emissions during hot-pressing of southern pine particleboard. Forest Products Journal 53 (3), 65-72.

Wang, S.Y., Yang, T.H., Lin, Y.T., Lin, C.J., Tsai, M.J., 2007. Properties of low-formaldehyde-emission particleboard made from recycled wood-waste particles sprayed with PMDI/PF resin. Building and Environment 42 (7), 2472-2479.

Wiglusz, R., Nikei, G., Igielska, G., Sitko, E., 2002. Volatile organic compounds emissions from particleboard veneered with decorative paper foil. Holzforschung 56 (1), 108-110.

Xu, W., Suchsland, O., 1998. Variability of particleboard properties from single- and mixed-species processes. Forest Products Journal 48 (9), $68-74$.

Yang, T.H., Tsai, M.J., Wang, S.Y., 2001. Characteristics of OSB made from PF-resin impregnated flakes. Forest Products Industries 20 (3), 227-237.

Yang, T.H., Lin, C.J., Wang, S.Y., Tsai, M.J., 2007. Characteristics of particleboard made from recycled wood-waste chips impregnated with phenol formaldehyde resin. Building and Environment 42 (1), 189-195. 